\title{
A Framework for Designing Learning Analytics Information Systems
}

\author{
Andy Nguyen \\ University of Oulu \\ Andy.nguyen@oulu.fi
}

\author{
Herman Wandabwa \\ Auckland University of \\ Technology \\ herman.wandabwa@aut.ac.nz \\ Anh Lan Le \\ Hanoi University of Natural \\ Resources and Environment \\ llanh@hunre.edu.vn
}

\author{
Aldrich Rasco \\ University of Auckland \\ a.rasco@auckland.ac.nz
}

\begin{abstract}
Learning analytics offers new opportunities in higher education, yet the design and development of educational data analytics are facing several challenges. There is a paucity of research and guidance supporting researchers and developers when it comes to designing, developing, and implementing learning analytics information systems in higher education. Hence, this study proposes a comprehensive conceptual framework for designing learning analytics information systems incorporating both computational and educational aspects. The framework provides systematic support for learning analytics researchers and designers. It is constructed based on the process and critical dimensions of learning analytics and instructional systems design. By applying the framework to analyze a previously published study, we provide a better understanding of its key qualities. Furthermore, the application of the framework to design a new learning analytics information system provides forward engineering support.
\end{abstract}

\section{Introduction}

The existing literature presents an increasing number of studies addressing the development and implementation of learning analytics [22, 24, 28]. Learning analytics have the potential to transform education systems as they can offer educational stakeholders, including both students, teachers, with predictive information [22, 23, 27], or reflective feedback and insights [3, 13]. Learning analytics is defined as "the application of data analytic techniques and tools for the purposes of understanding and enhancing learning and teaching" [25]. In contrast to educational data mining and academic analytics, learning analytics focus on the learners and their learning processes $[5,25,36]$. Learning analytics collect and analyze static and dynamic educational data to provide information about the learner profiles, learning contents, and context for scheduled or real-time modeling and prediction. While data analytics has been widely utilized and studied in the business context, learning analytics is still in a preliminary stage [25, 34]. Although it could be argued that learning analytics is similar to business analytics as another application of data analytics, learning analytics should be designed with careful considerations of learning theories [10]. Therefore, one cannot simply apply a known data analytics approach from business analytics into the educational context.

This study is driven by the unsuccessful search of existing frameworks and past literature to find an integrated framework that guided the design cycle of learning analytics information systems in higher education. The current frameworks neglected to reflect the design process, and the interactions between data analytics, educational theories, learning, and teaching practice. Another practical problem that motivated this study is the challenge of complexity in studying and designing educational data analytics. A comprehensive framework for designing learning analytics in education can help educational IS developers and researchers to understand the grounded foundation and identify the appropriate components for research, development, or implementation.

The purpose of this study is to explore what factors are crucial to different phases of learning analytics and suggest how studies on learning analytics information systems can be designed with an understanding of these factors. As a result, we develop and present a framework for designing learning analytics information systems, grounded in best practices from the literature. This framework can be both used as an analysis tool to help 
understand and evaluate the critical factors in previous studies. In particular, this paper aims to address the following research question: What are the fundamental steps and components to consider in the design, development, and implementation of a theory-based learning analytics information system (LAIS)?

This paper proceeds as follows: Firstly, we introduce the design science research (DSR) adopted to conduct this study. Then, we establish the theoretical and conceptual background for the design cycle and learning analytics by revising the existing frameworks founded in the literature. This is followed by the design and development of a framework for designing learning analytics information systems (DLAIS). Next, we demonstrate an example of DLAIS application by utilizing it in two different scenarios: (1) analyzing a published learning analytics information system design; and (2) designing a new learning analytics application. Finally, we discuss the contributions of the study and conclude by discussing its limitations and future research directions

\section{Methodology}

This study adopted the design science research (DSR) paradigm in Information Systems research to develop the conceptual framework as a design artifact. DSR is a lens or set of analytical and philosophical approaches that poises the positivist and interpretivist paradigms. DSR has become increasingly popular in both Information Systems (IS) [12, 16], and education research [2, 15]. Design refers to the creation of an innovative artifact while research is a process of discovering new insights into a phenomenon [38]. DSR has attempted to theory and practice in education and IS research by seeking the relationships between educational theory, designed artifact, and practice. The designed artifacts can be any object created for the purpose of solving an observed problem and helping to understand it [30]. They can include any constructs, social innovations, methods, models, instantiations, and new properties of social, technical, or informational resources [16]. DSR views a successful artifact as a combination of the design, the context, and theoretical contributions. DSR is essential for creating educational innovations, and understanding how, when, and why they work in practices.

\section{Theoretical and Conceptual Foundations}

\subsection{Learning Analytics Process}

Fundamental elements of an analytics system in educational contexts should allow a five-step process of capture, report, predict, act, and refine [6]. The flow through these steps is modeled by Romero \& Ventura (2015) as in Figure 1.

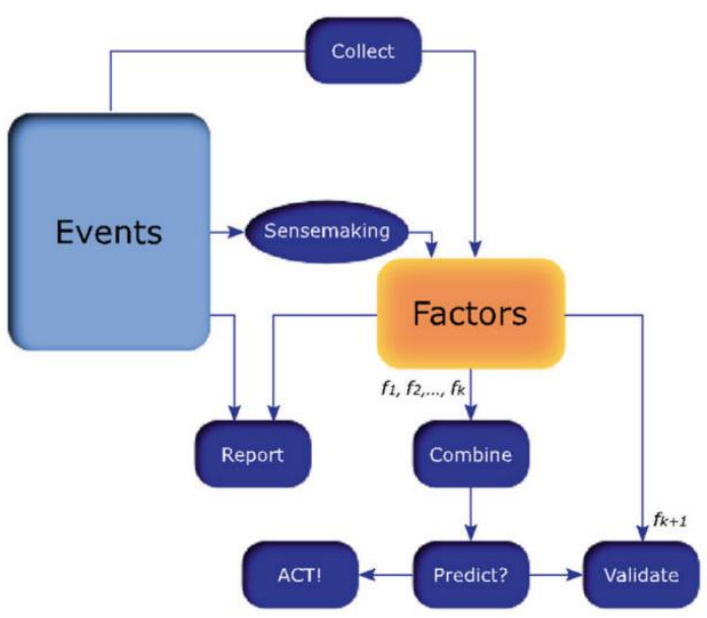

Figure 1: Steps of learning analytics [32]

Capture: The learning analytics process begins with the capture of raw data having low information density. Data are likely to be retrieved from a set of heterogeneous sources such as generated in the learning environment or stored in institutional databases. One of the richest and most common sources of data about learning is the learning management systems in which learning events occur and emit. The capture step also includes storing captured data in a digital storage for later use. In the past, it was difficult to access different forms of data from various sources [40]. Fortunately, the computerization of administrative and learning processes has transformed the relevant data into a digital form and exposed them to the network. Furthermore, the advent of emerging technology, especially in the field of big data, has extended the capability of handling big volumes. Big data technology has also enabled the segmentation of data into parts and storage locations thus reducing the processing time. The first requirement is the capability to capture detailed events emitted while students interact with the lecture recordings. The captured data should include actor identifier, timestamp, and event type such as video start, pause, skip and stop, and the location within the media. The system should also adopt advanced big data frameworks such as Apache Hadoop modules and related frameworks, for large-scale implementation and high performance.

Report: Reporting refers to providing information obtained from a learning environment to the stakeholders. This step of analytics focuses on processing raw data into information with reasonable, judicious density and visualizing the information. Intelligence density indicates the factor of useful 'decision-support information' that a decision-maker 
gets from using a system for a certain amount of time. In fact, a massive amount of data can be collected from different sources, and displaying all of these data can potentially cause information overload to the users. Information overload happens when the users receive too much information which may prevent them from interpreting necessary information [11]. Stakeholders, especially decision-makers, would require the displayed information in the form of density and presentation that can allow them to understand in a few seconds. As a result, it is essential to reduce intelligent density to a certain degree. The captured data are usually categorized in a set of various factors for this purpose. To further preclude information overload, many studies have addressed the area of information visualizations [39]. The second requirement relates to the visualizations of captured data that allow users to interpret meaningful information regarding student engagement with lecture recordings easily.

Predict: The analytics engine uses data factors collected from the previous steps to establish predictive models. Applying various methods and techniques, an analytics engine can derive models to predict anticipating events that will occur in the future. The most common types of predictive analytics used are statistical inference and machine learning. Given a diversity of educational data, there may also be ad-hoc predictive analytics apart from machine learning and statistical inferences. For example, the collected data can be manually processed to identify the indicators (Ferguson \& Shum, 2011). Romero \& Ventura (2015) suggested that the learning analytics system should produce predictive values for users. However, other studies have demonstrated that learning analytics can be significant without predictive outcomes as it is much important to offer a deep understanding of the learners and their learning processes $[3,21]$.

Act: Acting refers to manual or automatic responses based on the information obtained by processing captured data. There are a wide variety of actions ranging from brick-and-mortar activities and conversations to an automatic and significant change in learning resources. One of the simplest acts is an informal instruction in class. To date, learners and instructors have been the central actors in this step of learning analytics. For instance, the instructors may use reported information to adjust lecture contents. In the "Act" phase, the instructor or learner adjusts their practices corresponding to the outcomes of learning analytics.

Refine: Refine refers to a philosophical proposition rather than a set of methods and techniques. This step enables self-improvement in learning analytics by monitoring the learning analytics project and its impact on the community. It is noticed that there numerous internal and external factors influencing the development and implementation of learning analytics $[5,13]$. The influencing factors can also change over time thus it is essential to perform refinements continuously with scheduled updates. The refinement process also involves sharing knowledge and contributing to the body of knowledge.

\subsection{Critical Dimensions of Learning Analytics}

Previous studies have suggested that the fundamental dimensions of learning analytics consist of educational data, stakeholders, objectives, related

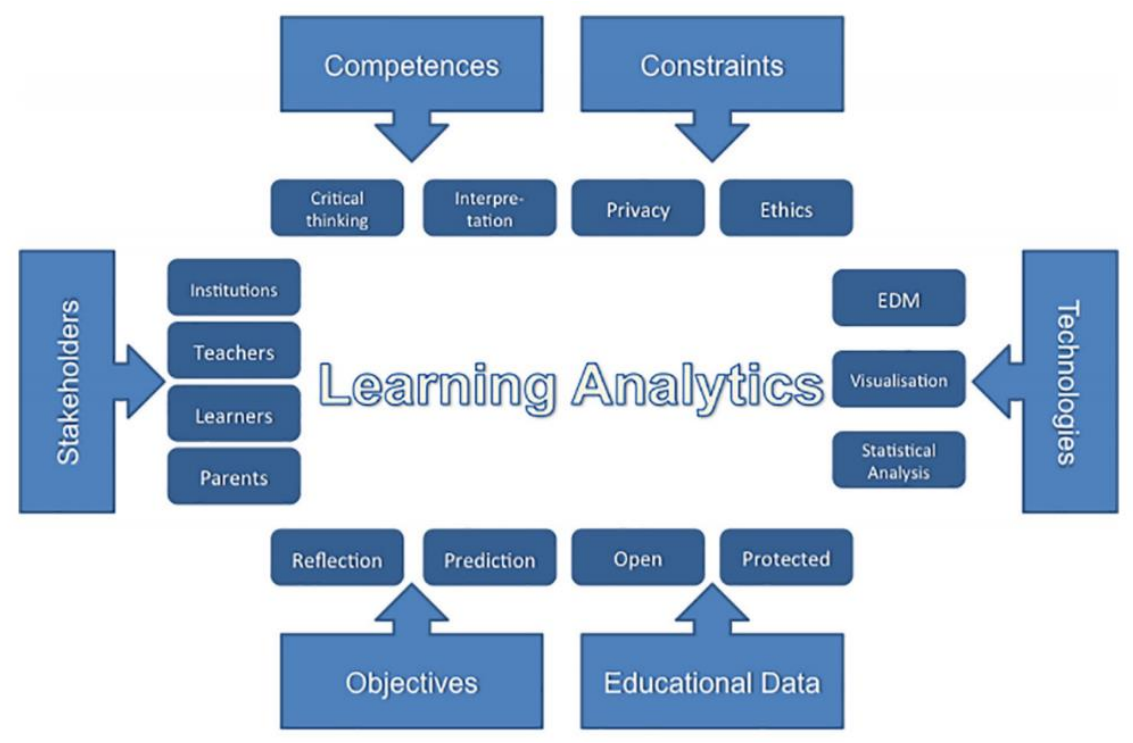

Figure 2: Critical dimensions of learning analytics [13] 
constraints, analytics methods, and techniques $[13,17$, 32]. In addition, it is essential to define the objectives clearly before building and studying educational data analytics [6]. Furthermore, previous studies have brought relevant ethical issues and dilemmas to attention [29, 37]. Assembling these components, Greller \& Drachsler (2012) proposed a framework for critical dimensions of learning analytics as demonstrated in Figure 2.

Educational stakeholders consist of various entity groups such as students, teachers, administrators, departments of education, or researchers. Ifenthaler \& Widanapathirana [17] proposed a model of learning analytics is addressing different stakeholder levels, namely micro, meso, macro, and mega. Micro-level relates to a learner's activities in the learning environments, both physical and online. Meso level refers to the teaching activities performed by teachers and tutors. Next, the macro-level represents the stakeholders related to institutional management whereas the mega level is the governance. Although this framework has shown an overall organization of education stakeholders, it would not offer significant support to the design and development of learning analytics. Greller \& Drachsler [13] suggest that stakeholders can be either data subjects or data clients. Data subjects generate educational data by interacting with educational systems. Whereas data clients receive and manage the products of learning analytics. For instance, the system can capture data of student learning interaction and navigation path then produce reports to the lecturers for a better understanding of student engagement with learning. Accordingly, the learner is a data subject in this case. They generate data while leaving digital footprints related to their use of learning materials on the Learning Management System (LMS). The lecturer gets entitled to receive reported information thus being identified as a data client. In some cases, a stakeholder can act as both a data subject and a data client, i.e., the stakeholder obtains outcome processed from their data to reflect on themselves. An example should be the case that a student receives information about their learning engagement thus be able to selfevaluate their learning process. Identification of data subjects and data clients leads to the determination of relevant data input and information output.

The objectives of data analytics in education can be either reflective or predictive. Reflection focuses on self-observation and self-evaluation of a data client for supporting decision-making and suitable interventions. For example, a learner can reflect on their learning process and be aware of their learning strategies, engagement, and performance. Moreover, reflection may involve information obtained from other stakeholders such as in the case of teachers reflect their teaching performance based on data collected from students. Nguyen, Gardner, \& Sheridan [25] suggested that stakeholders from the higher stakeholder level can utilize data collected from lower ones to reflect themselves and vice versa. For instance, teachers may consider their students' learning performance and the influences of institutional tactics to self-evaluate their performance. This reflects the multidimensional nature of educational data flows [10, 32].

Probabilistic prediction is the other main group of learning analytics objectives [17, 35]. Probabilistic prediction utilizes data mining and machine learning techniques to analyze a large collection of datasets to provide predictions for future events. This distinction is further demonstrated in studies using learning analytics to inform at-risk students for early interventions [8, 31, 36]. However, caution must be considered as prior studies recognized related issues such as privacy and ethical concerns, and potential limitation of a learner's potential [7, 13] concerning planned behavior [1].

Data analytics can gather a massive amount of educational data from several educational information systems such as the Learning Management System (LMS). Stakeholders' activities produce data every day by interacting with the computer-based platforms. Big data and data analytics technologies have enabled the real-time capture and process of dynamic data. Furthermore, the technologies also allow storing a massive data volume. However, not all data are used for the defined objectives [20]. One of the biggest challenges for learning analytics is to determine a relevant set of data and exclude the ineffective data to avoid data overload. The design of learning analytics should define and predict an effective set of indicators for the assessment of learning and teaching.

Previous studies have raised several ethical concerns related to the use of educational data [29, 37]. Research suggests that educational data analytics should consider data privacy, security, and transparency It follows that based on the restriction of access, educational data can also be categorized into open and protected data [13]. The availability of relevant data is critical to select appropriate instruments, including analytic methods and reporting techniques. As a result, ethical concerns are recognized as one of the external constraints from the surrounding environments that can impact the implementation of learning analytics in education [13]. These constraints include but are not limited to ethical, legal, and social factors. Internal limitations describe several human factors that impact on learning analytics directly or indirectly, such as competencies and acceptance [13]. Similar to the influence of external constraints, internal constraints also affect the implementation of learning analytics. 


\subsection{Instructional Systems Design (ISD)}

In the context of education, the ADDIE model is a well-known model that outlines generic processes of systematic instructional design [4]. The model represents a descriptive guideline for building effective instructional design in five phases including analysis, design, development, implementation, and evaluation. The analysis phase involves the designer in identifying the learning problem, the user needs, existing knowledge, and defining the goals and objectives. As ADDIE model is used for instructional design, the design phase is a process of specifying learning objectives systematically, often with storyboards and prototypes. In the context of learning analytics, this study refers to the design phase to the specifications of critical dimensions of learning analytics design. The implementation develops and applies a procedure to investigate the proposed design in action. During the implementation, the design can impact on the existing practices and knowledge of the targeted audience. The evaluation of the design consists of formative and summative processes. Formative evaluation occurs at each stage of the ADDIE process to be able to identify and apply the early intervention to the design. A summative evaluation is conducted at the end of the project to test the proposed design and gather feedback from the users.

\section{A Framework for Designing Learning Analytics Information Systems}

From the above analysis of the current three design perspectives, this study has developed a design framework for learning analytics that offers an overview of the design process and associated dimensions. Figure 3 shows how the components of learning analytics relate to each design phase and how the design of a learning analytics information system interacts with educational theories and practices.

The existing theories and frameworks have recognized important phases and dimensions of learning analytics. However, there is a paucity of relevant frameworks guiding learning analytics from the design science perspectives. Furthermore, the current studies have not demonstrated the interrelation of the design of learning analytics with the theories and practices of learning and teaching. Gašević et al. [10] remind that "let's not forget learning analytics are about learning." They should integrate the computational aspects within the prevailing educational research. Learning analytics should position itself beyond the state of simply

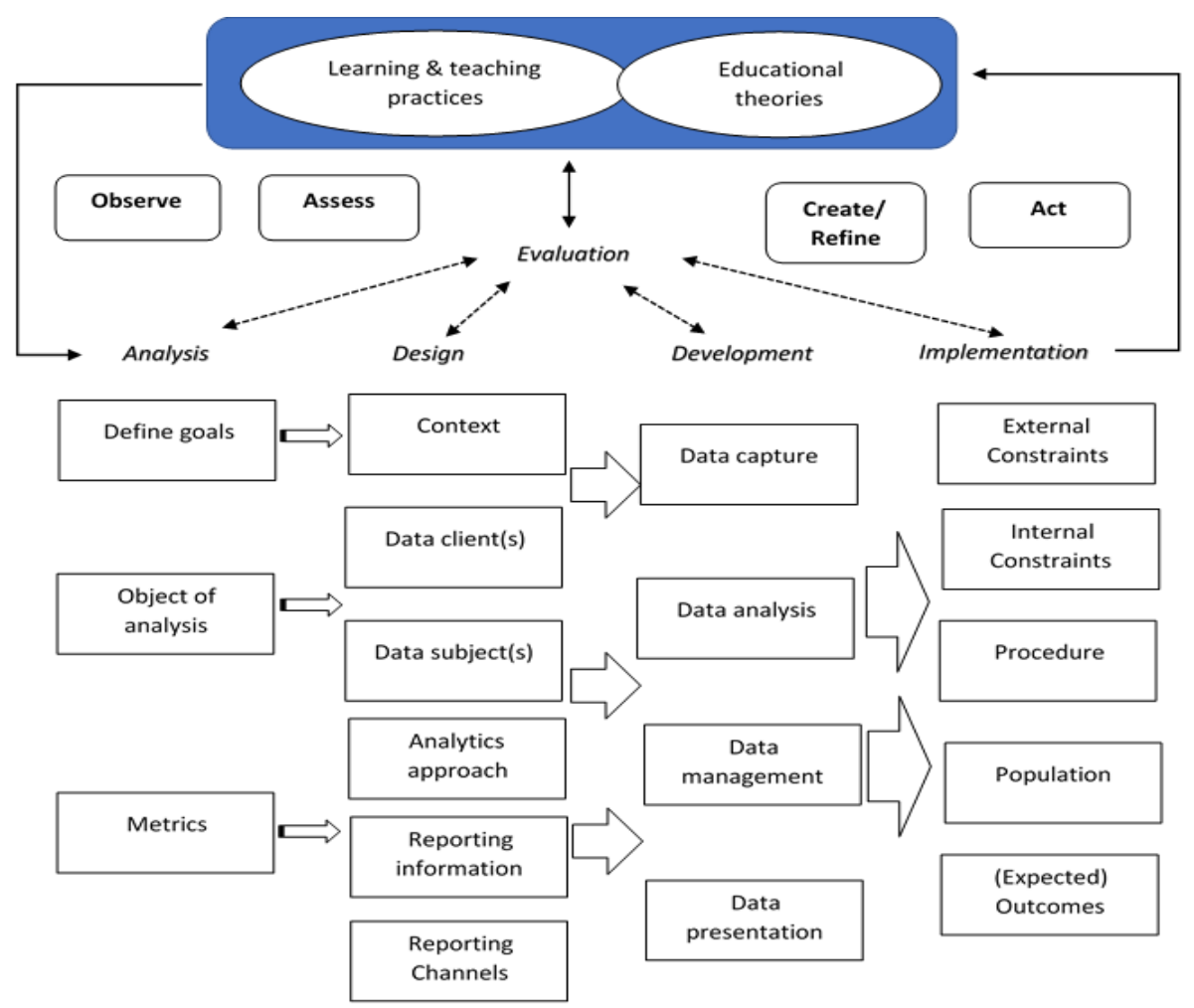

Figure 3: A Framework for Designing Learning Analytics Information Systems (DLAIS) 
transforming educational data into information. The design and development of educational data analytics should complement the educational theory to enhance educational activities and benefit all the stakeholders.

Accordingly, DLAIS framework reflects how the design process relates to educational theories and practices. The evaluation process mediates each phrase with the knowledge base and learning and teaching practices. This process also contributes to the sharing of knowledge by refining the existing theories. Furthermore, the observation of current practices and knowledge of educational theories support the analyze phase directly. On the other hand, the implementation can modify or improve the learning and teaching practices while contributing novice knowledge from the DSR perspective.

DLAIS consists of five iterative phases, namely 1) Analysis, 2) Design, 3) Development, 4) Implementation, and 5) Evaluation. During the analysis phase, the designer retrieves knowledge from the literature and observes learning and teaching practices to define the goals of the design. The identification of an analysis object defines the scope of the design and the targeted institutional level. An analysis of applicable metrics based on educational theories is important to verify the usefulness and effectiveness of the learning analytics application. The design phase refers to the specifications of related objects including the learning and teaching context, data client, data subject(s), analytics approach, reporting information, and channels. Based on the design specifications, the development applies specific technological tools or methods of data analytics. Finally, the implementation and evaluation of the design can alter learning and teaching practices and extend our understandings of the studied objects and other related characteristics.

The five iterative phases of DLAIS will continuously engage with educational theories and practices. The observation from learning and teaching practice incorporating relevant learning theories will inform the design and development of theory-based LAIS. While the implementation of LAIS will provide evidence for evaluating the designed artifact, the use of LAIS will allow for assessing current learning and teaching practice as well as for validating the existing theories and formulating new learning and design theories.

\section{Application of DLAIS}

By way of illustration, we applied DLAIS to analyze a published learning analytics study and to design a learning analytics application. First, Table 1 demonstrates the use of DLAIS in examining "ALAS-

Table 1: An example of applying DLAIS to analyse ALAS-KA

\begin{tabular}{|c|c|c|c|c|}
\hline Analyse & Design & Development & Implementation & Evaluation \\
\hline $\begin{array}{l}\text { Observation: } \\
\text { Khan Academy } \\
\text { system does not } \\
\text { offer sufficient } \\
\text { analytical } \\
\text { information } \\
\text { Theories: } \\
\text { Learning self- } \\
\text { regulation } \\
\text { Define goals: } \\
\text { Creating a system } \\
\text { to provide students } \\
\text { and teachers with } \\
\text { visual information } \\
\text { Object of analysis: } \\
\text { Course-level: } \\
\text { Learning progress } \\
\text { Metrics: } \\
\text { Time spent in each } \\
\text { resource. } \\
\text { A percentage of } \\
\text { resources accessed } \\
\text { or avoidance }\end{array}$ & $\begin{array}{l}\text { Context: } \\
\text { e-learning } \\
\text { Data subject: } \\
\text { Students } \\
\text { Data clients: } \\
\text { Students; } \\
\text { Teacher } \\
\text { Analytics } \\
\text { approach: } \\
\text { Content and } \\
\text { context analytics } \\
\text { Reporting } \\
\text { information: } \\
\text { How is the } \\
\text { learning progress } \\
\text { of the students } \\
\text { (details in } \\
\text { Appendix 1) } \\
\text { Reporting } \\
\text { channels: Online } \\
\text { Dashboard }\end{array}$ & $\begin{array}{l}\text { Data capture: } \\
\text { ALAS-KA } \\
\text { extracting module } \\
\text { (Task system) } \\
\text { Khan Academy } \\
\text { Data Models } \\
\text { Google App Engine } \\
\text { (GAE) } \\
\text { Data analysis: } \\
\text { ALAS-KA data } \\
\text { models } \\
\text { Cron jobs } \\
\text { Queue system } \\
\text { ALAS-KA } \\
\text { processing system } \\
\text { Data storage and } \\
\text { management: } \\
\text { Not available } \\
\text { Data presentation: } \\
\text { The Google Charts } \\
\text { API } \\
\text { JavaScript } \\
\text { HTML5/SVG }\end{array}$ & $\begin{array}{l}\text { External constraints: } \\
\text { Privacy concerns } \\
\text { Internal constraints: } \\
\text { Interpretation of the } \\
\text { results } \\
\text { Procedure: } \\
\text { System } \\
\text { Population: Students } \\
\text { studied at university } \\
\text { Sample: } \\
\text { >300 students studied } \\
\text { at Universidad Carlos } \\
\text { III de Madrid (UC3M) } \\
\text { Outcomes: Exercise } \\
\text { solving habits; } \\
\text { Variations in affective } \\
\text { state } \\
\text { Learning persistence }\end{array}$ & $\begin{array}{l}\text { Act: } \\
\text { Students' self- } \\
\text { reflection } \\
\text { Teachers' } \\
\text { analysis of class } \\
\text { tendencies } \\
\text { Create/ Refine: } \\
\text { Learning } \\
\text { analytics } \\
\text { technology can } \\
\text { provide } \\
\text { information } \\
\text { about efficiency, } \\
\text { behavioural, } \\
\text { motivation }\end{array}$ \\
\hline
\end{tabular}


Table 2: An example of applying DLAIS to design a learning analytics information system

\begin{tabular}{|l|l|l|l|l|}
\hline \multicolumn{1}{|c|}{ Analyse } & \multicolumn{1}{|c|}{ Design } & \multicolumn{1}{c|}{ Development } & \multicolumn{1}{c|}{ Implementation } & \multicolumn{1}{c|}{ Evaluation } \\
\hline Observation: & Context: & Data capture: & External constraints: & Act: Adjusting \\
Lecturers cannot & Students watching & Event-log tracker & Privacy concerns & lecture content in \\
monitor how their & lecture recordings & and recorder. & Internal constraints: & a timely manner \\
students watch & online & Data analysis: & Interpretation of the & Revising the \\
lecture recordings & Data subject: & Hadoop; & results & missing parts of \\
Theories: & Student & Luigi; & Procedure: & knowledge \\
Learning co- & Data client: & Map-reduce & Students watch lecture & Create/ Refine: \\
regulation & Lecturer & aggregation & recordings online & Applying \\
Define goals: & Analytics & algorithms & Their usage reported & learning \\
Creating a system & approach: & Data storage and & to lecturers & analytics \\
automatically & Content and & management: & automatically & technology to \\
informing the & context analytics & HDFS; & Population: Students & provide \\
lecturers about & Reporting & Split MongoDB; & studied at university & automatic \\
student activities & information: & MySQL & Sample: Students in a & information \\
on lecture & Completion & Data presentation: & few courses at a & about student \\
recordings & percentage. & Visualisation & university in New & engagement can \\
Object of analysis: & Segments with & dashboard in & Zealand & support adaptive \\
Course-level: & low views. & Python & Expected Outcomes: & teaching \\
Lecture recordings & Segments with & & Identifying at-risk & effectively \\
Metrics: & high replays & & students; & \\
Unique views; & Reporting & & Identifying & \\
Watching time, & channels: & & problematic segments; & \\
Watching or & Online Dashboard & & & \\
Replay segments; & & & & \\
\hline
\end{tabular}

KA: A learning analytics extension for better understanding the learning process in the Khan Academy platform" by Ruipérez-Valiente, MuñozMerino, Leony, \& Kloos [33]. The learning analytics design was randomly selected from published papers about the design of learning analytics information systems. The use of DLAIS, in this case, aids the analysis of an existing LAIS system design to identify its key components. Particularly, it can be applied for a comparative analysis with other systems or further improvement and development.

Table 2 illustrates another example of applying DLAIS to design a learning analytics information system that can automatically inform the lecturers about student activities on lecture recordings. This system design relates to learning co-regulation theories [14]. The system aims to automatically inform the lecturers about student activities on lecture recordings so that the lecturers can effectively co-regulate students' engagement with learning.

For the evaluation of DLAIS, we have developed and implemented a learning analytics information system (LAIS) based on the identified constructs. We implemented the designed LAIS in four courses at the university to support teachers to monitor the class engagement with lecture recording. In the evaluation, the teacher reported that the designed LAIS was useful to support them in teaching and assessing lecture content. The evaluation through the implementation of the system also led to the development of the design principles for LAIS that we reported in another study [26].

\section{Discussion}

Learning analytics provides a range of new research opportunities and practical applications to leverage our growing understanding of learning and to support learning and teaching effectively [22]. While previous learning analytics frameworks have provided useful dimensions for utilizing educational data, there is no framework found to guide the design and development of learning analytics information systems (LAIS). The conceptual research in this paper has led us to present a holistic framework for a framework for designing learning analytics information systems (DLAIS).

DLAIS framework could be used to either analyzing an existing LAIS or guide and support the design of a new one. Since the design, development, and implementation of a LAIS is a complicated process involving various skills and knowledge from multiple disciplines such as education, information systems, software engineering, and data science $[9,26]$, an 
explicit model of key constructs for a LAIS is essential. Accordingly, DLAIS informs the main constructs in each design phase to the research team.

The incorporation of the DSR perspective in the construction of DLAIS allows IS researchers for convenient adoption of the framework to both develop an effective LAIS and report a vigor DSR study. Although previous studies have demonstrated the potential of LA for transforming education, there has been little attention paid to the design and implementation of IS with LA capabilities [26]. As a result, the study attempts to propose essential guidelines and a unified framework in hope of that educational IS researchers can unite the forces with the learning scientists and other research communities to push the LA agenda forward

This conceptual study responds to the recent calls to perform theory-based LA research [10, 19] and to support the application of learning analytics in higher education [18, 24]. The framework proposed in this paper is easy to follow to design a theory-based learning analytics information system. Learning analytics encompasses multiple disciplines thus the framework acts as a bridge between concepts and models from those different fields. As a result, DLAIS can fasten the learning curve of newcomers to educational data analytics.

\section{Conclusion}

This study aims to propose a unified framework for designing learning analytics information systems (DLAIS). We have reviewed and incorporated and the existing LA frameworks to identify and align the key constructs of LA systematically to conceptualise DLAIS. We demonstrated two examples of applying DLAIS to 1) analysing and reverse-engineering an existing LAIS, and 2) design and implement a novel LAIS to support teaching at university.

DLAIS allows IS Education researchers and practitioners to systematically analyze and ultimately improve the design, development and implementation of learning analytics information systems. DLAIS provides practical guidelines as well as informs important components in the design process of LAIS. By applying DLAIS, researchers and practitioners could design and development more satisfactory systems that can deliver great benefits to the stakeholders.

This study has some limitations. For instance, rather than centering on the fundamental dimensions of LA and its process, DLAIS could be conceptualised differently based on the insights from LA stakeholders. Another limitation is the current limited demonstration and evaluation of DLAIS. Additional work is needed to apply DLAIS in different contexts to validate its generalizability. Since sustainable efforts are needed to realise the use of LAIS in education [24], future works would continue the efforts to apply DLAIS to design effective LAIS. Furthermore, future research may refine DLAIS framework through the development and implementation of different types of LAIS.

\section{References}

[1] Ajzen, I., "The theory of planned behavior", Organizational Behavior and Human Decision Processes 50(2), 1991, pp. 179-211.

[2] Anderson, T., and J. Shattuck, "Design-Based Research: A Decade of Progress in Education Research?", Educational Researcher 41(1), 2012, pp. 16-25.

[3] Blikstein, P., "Using learning analytics to assess students' behavior in open-ended programming tasks", Proceedings of the International Conference on Learning Analytics and Knowledge, ACM (2011), 110116.

[4] Branch, R.M., Instructional Design: The ADDIE Approach, Springer US, Boston, MA, 2009.

[5] Brown, M., "Learning analytics: Moving from concept to practice", EDUCAUSE Review, 2012, pp. 15 .

[6] Campbell, J.P., and D.G. Oblinger, "Academic Analytics”, EDUCAUSE Review 42(4), 2007, pp. 4057.

[7] Chatti, M.A., A.L. Dyckhoff, U. Schroeder, and H. Thüs, "A reference model for learning analytics", International Journal of Technology Enhanced Learning 4(5/6), 2012, pp. 318-331.

[8] Clow, D., "The learning analytics cycle: closing the loop effectively", Proceedings of the 2nd International Conference on Learning Analytics and Knowledge, ACM (2012), 134-138.

[9] Daniel, B., "Big data and analytics in higher education: Opportunities and challenges", British journal of educational technology, 2015.

[10] Dawson, S., D. Gašević, and G. Siemens, "Let's not forget: Learning analytics are about learning", TechTrends, 2015.

[11] Edmunds, A., and A. Morris, "The problem of information overload in business organisations: a review of the literature", International journal of information management 20(1), 2000, pp. 17-28.

[12] Gregor, S., and A.R. Hevner, "Positioning and presenting design science research for maximum impact", MIS quarterly 37(2), 2013, pp. 337-355.

[13] Greller, W., and H. Drachsler, "Translating learning into numbers: A generic framework for learning analytics", Educational technology \& society 15(3), 2012, pp. 42-57.

[14] Hadwin, A.F., S. Järvelä, and M. Miller, "Self- 
regulation, co-regulation, and shared regulation in collaborative learning environments.", In D.H. Schunk and J.A. Greene, eds., Handbook of Self-Regulation of Learning and Performance. Routledge, New York, NY, 2018, 83-106.

[15] Hake, R.R., "Design-based research in physics education research: A review", Handbook of Design Research Methods in Mathematics, Science, and Technology Education: Erlbaum, 2007.

[16] Hevner, A.R., S.T. March, J. Park, and S. Ram, "Design science in information systems research", MIS quarterly 28(1), 2004, pp. 75-105.

[17] Ifenthaler, D., and C. Widanapathirana, "Development and validation of a learning analytics framework: Two case studies using Support Vector Machines", Technology, Knowledge and Learning 19(1-2), 2014, pp. 221-240.

[18] Järvelä, S., D. Gašević, T. Seppänen, M. Pechenizkiy, and P.A. Kirschner, "Bridging learning sciences, machine learning and affective computing for understanding cognition and affect in collaborative learning", British Journal of Educational Technology, 2020, pp. bjet.12917.

[19] Kent, C., and M. Cukurova, "Investigating collaboration as a process with theorydriven learning analytics", Journal of Learning Analytics 7(1), 2020, pp. 59-71.

[20] Krumm, A.E., R.J. Waddington, S.D. Teasley, and S. Lonn, "Learning analytics", The SAGE Encyclopedia of Educational Technology, 2014. http://link.springer.com/10.1007/978-1-4614-3305-7

[21] Leony, D., A. Pardo, L. de la Fuente Valentín, D.S. de Castro, and C.D. Kloos, "GLASS: A learning analytics visualization tool", Proceedings of the 2nd International Conference on Learning Analytics and Knowledge, ACM (2012), 162-163.

[22] Nguyen, A., L. Gardner, and D. Sheridan, "A multi-layered taxonomy of learning analytics applications", Pacific Asia Conference on Information Systems (PACIS) 2017 Proceedings, (2017), 54.

[23] Nguyen, A., L. Gardner, and D. Sheridan, "Building an ontology of learning analytics", Pacific Asia Conference on Information Systems (PACIS) 2018 Proceedings, (2018).

[24] Nguyen, A., L. Gardner, and D. Sheridan, “A Design Methodology for Learning Analytics Information Systems: Informing Learning Analytics Development with Learning Design", Hawaii International Conference on System Sciences (HICSS), (2020).

[25] Nguyen, A., L. Gardner, and D. Sheridan, "Data Analytics in Higher Education: An Integrated View", Journal of Information Systems Education 31(1), 2020.

[26] Nguyen, A., T. Tuunanen, L. Gardner, and D.
Sheridan, "Design Principles for Learning Analytics Information Systems in Higher Education", European Journal of Information Systems (EJIS), 2020.

[27] Noroozi, O., I. Alikhani, S. Järvelä, P.A. Kirschner, I. Juuso, and T. Seppänen, "Multimodal data to design visual learning analytics for understanding regulation of learning", Computers in Human Behavior 100, 2019, pp. 298-304.

[28] Pardo, A., J. Jovanovic, S. Dawson, D. Gašević, and N. Mirriahi, "Using learning analytics to scale the provision of personalised feedback", British Journal of Educational Technology 50(1), 2019, pp. $128-138$.

[29] Pardo, A., and G. Siemens, "Ethical and privacy principles for learning analytics", British journal of educational technology 45(3), 2014, pp. 438450.

[30] Peffers, K., T. Tuunanen, and M.A. Rothenberger, "A design science research methodology for information systems research", Journal of Management Information System, 2007.

[31] Pistilli, M.D., K. Arnold, and M. Bethune, "Signals: Using academic analytics to promote student success", EDUCAUSE Review, 2012.

[32] Romero, C., and S. Ventura, "JA Larusson, B. White (eds): Learning analytics: From research to practice", Technology, Knowledge and Learning 20(3), 2015, pp. 357-360.

[33] Ruipérez-Valiente, J.A., P.J. Muñoz-Merino, D. Leony, and C.D. Kloos, "ALAS-KA: A learning analytics extension for better understanding the learning process in the Khan Academy platform", Computers in Human Behavior 47, 2015, pp. 139-148.

[34] Siemens, G., "Learning analytics: The emergence of a discipline", American Behavioral Scientist, 2013, pp. 0002764213498851.

[35] Siemens, G., and R. Baker, "Learning analytics and educational data mining: towards communication and collaboration", Proceedings of the 2nd International Conference on Learning Analytics and Knowledge, ACM (2012), 252-254.

[36] Siemens, G., and P. Long, "Penetrating the fog: Analytics in learning and education", EDUCAUSE Review 46(5), 2011, pp. 30.

[37] Slade, S., and P. Prinsloo, "Learning analytics ethical issues and dilemmas", American Behavioral Scientist 57(10), 2013, pp. 1510-1529.

[38] Vaishnavi, V., and B. Kuechler, "Design science research in information systems", Association for Information Systems, 2005.

[39] Vieira, C., P. Parsons, and V. Byrd, "Visual learning analytics of educational data: A systematic literature review and research agenda", Computers and Education 122, 2018, pp. 119-135.

[40] Worsley, M., "Multimodal Learning 
Analytics' Past, Present, and, Potential Futures", Learning Analytics \& Knowledge Conference, (2018). 